\title{
Predictive and Prognostic Role of Tumor Infiltrating Lymphocytes in Breast Cancer Patients With Different Molecular Subtypes: a Meta-Analysis
}

\section{Zhao-hua Gao ( $\nabla$ gooscigol@163.com )}

Cancer Hospital of China Medical University

\section{Cun-xin Li}

Liaoning Cancer Hospital and Institute

Ming Liu

Liaoning Cancer Hospital and Institute

Jia-yuan Jiang

Liaoning Cancer Hospital and Institute

\section{Research}

Keywords: breast cancer, tumor infiltrating lymphocytes, molecular subtype, prognosis, prediction, metaanalysis

Posted Date: July 17th, 2020

DOI: https://doi.org/10.21203/rs.3.rs-42520/v1

License: (c) (1) This work is licensed under a Creative Commons Attribution 4.0 International License. Read Full License 


\section{Abstract}

\section{Background}

Whether TILs plays different roles in different molecular subtypes breast cancer remains unknown. The prognostic and predictive value of TILs in different molecular subtypes breast cancer is still controversy. The aim of our meta-analysis is to assess the prognostic and predictive value of TILs in different molecular subtypes breast cancer by summarizing all relevant studies including multivariate analysis.

\section{Methods}

PubMed, Embase, EBSCO, ScienceDirect, Cochrane Database and the Web of Science were comprehensively retrieved (until March 2020). Hazard ratio (HR), odds ratio (OR) and their $95 \%$ confidence intervals $(\mathrm{Cl})$ were used as effect measures to perform our meta-analysis. Random effect model was used. Stata software, version 15 (2017) (Stata Corp, College Station, TX, USA) was used to carried out statistical analysis.

\section{Results}

Thirty-three studies including 18170 eligible breast cancer patients were analyzed. The meta-analysis showed that patients with high TILs expression were significantly correlated with increased pCR after neoadjuvant chemotherapy in HER2 enriched molecular subtype (OR $=1.137,95 \% \mathrm{Cl}[1.061 \sim 1.218], \mathrm{p}$ $<0.001$ ) and TNBC molecular subtype breast cancer ( $\mathrm{OR}=1.120,95 \% \mathrm{Cl}$ [1.061 1.182], $\mathrm{p}<0.001)$. But, patients with high TILs expression were not significantly related to high pCR in luminal molecular subtype breast cancer after neoadjuvant chemotherapy ( $\mathrm{OR}=1.154,95 \% \mathrm{Cl}[0.789 \sim 1.690], \mathrm{p}=0.460)$. We carried out this meta-analysis on HR for OS and DFS to assess the prognostic value of TILs in breast cancer with different molecular subtypes more deeply. Our meta-analysis confirmed that high TILs had relationship with a significantly improved DFS in HER2 enriched molecular subtype [HR=0.940, 95\% $\mathrm{Cl}(0.903 \sim 0.979)$, $p=0.003$ ] and TNBC molecular subtype breast cancer patients [HR=0.907, 95\% $\mathrm{Cl}(0.862 \sim 0.954), p<0.001]$. However, high TILs was not correlated with a significantly better DFS in luminal molecular subtype breast cancer patients [HR=0.998, 95\% Cl $(0.977 \sim 1.019), p=0.840]$. Furthermore, the results confirmed that high TILs had significant relationship with a better OS in HER2 enriched molecular subtype [HR=0.910,95\% Cl (0.866 0.957), $p<0.001]$ and TNBC molecular subtype breast cancer patients [HR=0.869, 95\% $\mathrm{Cl}$ (0.836 0.904), $p<0.001]$. Conversely, the summarized results indicated that high TILs was significantly correlated with a poor OS in luminal molecular subtype breast cancer patients $[\mathrm{HR}=1.077,95 \% \mathrm{Cl}$ (1.016 1.141), $p=0.012]$.

\section{Conclusions}

Our meta-analysis confirms that high TILs is correlated with favourable survival and predicts pathological complete response in breast cancer patients with TNBC molecular subtypes and HER2-enriched molecular subtypes. 


\section{Background}

Breast cancer is one of the most common malignant tumors in women [1], which is still the second reason of cancer-related death in women around the world [2]. At present, the forecast of the prognosis is remain not ideal, and specific predictor is required to enhance the individualized therapy effect. The complex interaction between the immune system and cancer cells plays a vital role in controlling and eradicating cancer, and is regulated by a delicate balance between activation and suppression signals[3]. Research on the microenvironment of tumor can disclose the complex correlation between the immune system and the biological behavior of cancer cells. For restricting the development of breast cancer, it is very important to understand the tumor microenvironment.

More and more evidence indicates that the tumor microenvironment plays an important role in tumor formation, growth, invasion and metastasis. Tumor- infiltrating lymphocytes (TIL) play a vital role in regulating the tumor microenvironment, promoting or inhibiting canceration and cancer progression. Tumor-infiltrating lymphocytes (TIL) have emerged as potentially important prognostic and/or predictive biomarkers for breast cancer $[4,5]$. While supplying valuable information, the heterogeneity of experimental design and TILs assessment hindered a more comprehensive understanding of the biological value of TILs. However, the prognostic value of TIL remains complex and controversial. Breast cancer is a clinical and molecular heterogeneous disease, and various factors determine the prognosis and response to treatment.

Thus, we carried out this meta-analysis, aiming to estimate the prognostic and predictive value of tumor infiltrating lymphocytes in patients with different molecular subtypes breast cancer.

\section{Material And Methods}

\section{Retrieval strategy}

Embase, PubMed, EBSCO, Cochrane Database,ScienceDirect and the Web of Science were comprehensively retrieved for researches exploring the prognostic and predictive relationship between tumor-infiltrating lymphocytes and breast cancer with different subtypes (without time, place of publication or language restrictions $\square$ until March 2020). No retrieval restrictions were used. In addition, the reference lists of searched reviews and researches were examined to further identify potentially related articles. The main retrieval terms applied were "breast cancer", "breast carcinoma", "neoadjuvant chemotherapy", "TILs", "Tumor-infiltrating lymphocytes", "prognosis", "change".

\section{Selection standards}

In order to ensure the accuracy and reliability of our analysis, we selected qualified studies according to the following standards: (i) The prognostic or predictive value of TILs testing in different subtypes breast cancer with at least one relevant outcome indicator has been reported in the research or can be computed based on published data. (ii) Choose high-quality studies that perform multivariate analysis on pCR or 
survival data such as DFS, OS. (iii) Hazard ratio (HR), odds ratio (OR) and their $95 \%$ confidence interval (Cl) were reported; or, they can be calculated according to the data of outcomes DFS, OS and pCR. (iiii) The samples were taken from the core-needle biopsy specimens or the surgical specimens after operation.

Two authors (Zhao-hua Gao and Ming Liu) independently performed literature retrieval and determined qualified researches according to the inclusion standards. Differences between the authors were settled by discussion and consensus. If no agreement can be reached, the final outcome is determined by a thirdparty researcher (Cun-xin Li). If there are more than one publications on the basis of the same patient groups, the most informational research was used.

\section{Research quality appraisal and data collection}

Our data was collected according to Cochrane guidelines [6]. Two authors (Zhao-hua Gao, Ming Liu) examined eligible researches independently, and any differences between the authors were settled by discussion and consensus. The following data for our meta-analysis were collected: Publication time, first author, country, study design, baseline patient characteristics, age range, treatment type, molecular subtypes, ethnicity, follow-up duration, TILs cutoff value, TILs position, outcomes (pCR, DFS, OS), hazard ratio (HR), odds ratio (OR) and 95\% confidence interval $(\mathrm{Cl})$. The Newcastle Ottawa scale (NOS) criteria was used to evaluate the quality of the selected eligible researches[7]. Funnel plot was applied to estimate the publication bias. The researches selected in our meta-analysis had obtained written informed consent from all patients and were carried out according to the clinical practice principles, all local regulations and Helsinki Declaration.

\section{Statistic analysis}

In this meta-analysis, we chose pathological complete response (PCR) as a predictor of neoadjuvant chemotherapy (NAC) for breast cancer. We assessed the overall odds ratio (OR) and its $95 \%$ confidence interval (CI) of qualified studies for the predictive value of TILs in NAC of breast cancer. Overall survival (OS) and disease-free survival (DFS) were used as prognostic outcomes in our meta-analysis. In the meta-analysis, hazard ratio (HR) and its $95 \%$ confidence interval $(\mathrm{Cl})$ were used as the effect scales of prognosis. The association between TILs and clinicopathological parameters were evaluated using odds ratio (OR) and its $95 \%$ confidence interval $(\mathrm{Cl})$. If the $\mathrm{HR}$ or OR and its $95 \% \mathrm{Cl}$ can not be obtained directly from the original article, we can use the available data to calculate with the software designed by Tierney et al[8]. The $\mathrm{Q}$ test was used to calculate the heterogeneity between studies and the $\mathrm{I}^{2}$ value represents the size of the heterogeneity [9]. If $\mathrm{I}^{2}$ value $>40 \%$ showed high heterogeneity [6]. Supposing that the heterogeneity was high, a random effects model was utilized. If not, a fixed-effect model was applied. P value was set as $<0.05$, which was statistically significant. The clinicopathological parameters, prediction and prognostic indicators of all relevant studies were pooled analyzed. At the same time, subgroup analysis was completed based on different ethnicity and different study design. Quality and homogeneity of results were estimated by sensitivity analysis. Utilize a funnel chart to test publication bias. 
Stata software, version 15 (2017) (Stata Corp, College Station, TX, USA) was used to carried out statistical analysis. This meta-analysis was guided by the recommendations of the Preferred Reporting Items for Systematic Reviews and Meta-analyses (PRISMA) [10].

\section{Results}

\section{Baseline characteristics of qualified researches}

In the systematic literature retrieval, we found 617 researches. By reviewing the title and abstract, 74 possible related researches were identified. In the remaining 74 studies, 41 of these studies were later excluded because they did not meet the selection standards. Eventually, we determined that 33 researches met the inclusion standards.[4, 5, 11-41] Fig. 1, summarized the search and screening process. The 33 researches comprised 18170 qualified patients with breast cancer (sample capacity, median: 331 [50-3771], mean: 550). These studies were published between 2010 and 2020 from the Europe, America, Australia and Asia (Spain, France, Italy, United Kingdom, Belgium, Finnish, Germany, Ireland, USA, Canada, Australia, Japan, Korea, China ). Eligible researches evaluated TILs by hematoxylin and eosin stained sections. Twelve studies provided OR on pCR to complete the meta-analysis[13, 23, 25, $26,28,31,33-35,37,38,41]$. Fifteen of these researches provided HRs data of DFS or OS and we performed the pooled analysis. Twelve researches furnished HRs data of DFS $[5,13,15-17,24,26,29-$ $31,37,40]$, and ten researches furnished HRs data of $\mathrm{OS}[5,13,15,17,18,20,21,24,26,29]$. Table 1 , summarized the main baseline characteristics. We estimated the quality of selected researches based on the NOS and As shown in Table 2.

\section{Relationship of the lymphocyte-predominant breast cancer (LPBC) with clinicopathological parameters}

\section{T stage}

The incidence of LPBC in the T3,T4 group was lower than T1,T2 group, the difference achieve statistical significance [ $\left.O R=0.646,95 \% \mathrm{Cl}(0.542,0.771), \mathrm{I}^{2}=0.0 \%, \mathrm{z}=4.85, \mathrm{p}<0.001\right]$. After that, subgroup analysis were conducted on different ethnicity [Europe: $O R=0.661,95 \% \mathrm{Cl}(0.546,0.800), \mathrm{I}^{2}=0.0 \%, z=4.25, \mathrm{p}<$ 0.001; Asia: $O R=0.516,95 \% \mathrm{Cl}(0.297,0.898), \mathrm{I}^{2}=0.0 \%, \mathrm{z}=2.34, \mathrm{p}=0.019 ;$ America: $\mathrm{OR}=0.695,95 \% \mathrm{Cl}$ $(0.294,1.643), z=0.83, p=0.407$ ] and different study design [RCT: OR $=0.663,95 \% \mathrm{Cl}(0.550,0.798), \mathrm{I}^{2}=$ $0.0 \%, z=4.33, p<0.001$; retrospective: $\left.O R=0.516,95 \% \mathrm{Cl}(0.297,0.898), l^{2}=0.0 \%, z=2.34, p=0.019\right]$. In the Asian group and the European group, the difference were statistically significant.

\section{Lymph node status}

The pooled analysis indicated that the incidence of the lymphocyte-predominant breast cancer (LPBC) detection between the lymph node metastasis group and the non lymph node metastasis group has no significant difference (overall: $O R=0.941,95 \% \mathrm{Cl} 0.681,1.298], I^{2}=76.4 \%, z=0.37, p=0.709$ ). After that, subgroup analysis were carried out on different ethnicity [Europe: $\mathrm{OR}=0.991,95 \% \mathrm{Cl}(0.633,1.551), \mathrm{I}^{2}=$ 
80.8\%, $z=0.04, p=0.968 ;$ Asia: $O R=1.013,95 \%$ Cl $(0.595,1.726), I^{2}=60.8 \%, z=0.05, p=0.962$; America: $\mathrm{OR}=0.549,95 \% \mathrm{Cl}(0.322,0.936), z=2.20, p=0.028]$. The difference was statistically significant in the America group.

\section{Histological type}

The incidence of the lymphocyte-predominant breast cancer (LPBC) was significantly different between the invasive ductal carcinoma and invasive lobular carcinoma groups (overall: $\mathrm{OR}=2.654,95 \% \mathrm{CI}[1.132$, $\left.6.223], I^{2}=68.0 \%, z=2.24, p=0.025\right)$. Then subgroup analysis were performed on different study design (RCT: $O R=4.735,95 \% \mathrm{Cl}[2.850,7.867], \mathrm{I}^{2}=0.0 \%, z=6.00, \mathrm{p}<0.001$; retrospective: $\mathrm{OR}=1.101,95 \% \mathrm{Cl}$ $\left.[0.622,1.951], I^{2}=0.0 \%, z=0.33, p=0.740\right)$. The difference was statistically significant in the RCT group.

\section{Histological grade}

The detection of the lymphocyte-predominant breast cancer (LPBC) in pathological specimen can show histological grading [III versus $\nabla$ and I, overall: $\mathrm{OR}=2.889,95 \% \mathrm{Cl}(2.218,3.762), \mathrm{I}^{2}=49.5 \%, \mathrm{z}=7.87, \mathrm{p}<$ 0.001]. After that, subgroup analysis were conducted on different ethnicity [Europe: $\mathrm{OR}=2.871,95 \% \mathrm{Cl}$ (2.290, 3.600), $I^{2}=25.5 \%, z=9.14, p<0.001$; Asia: OR = 5.636, 95\% Cl $(3.050,10.415), I^{2}=0.0 \%, z=5.52, p<$ 0.001; America: $\mathrm{OR}=1.659,95 \% \mathrm{Cl}(0.982,2.804), \mathrm{z}=1.89, \mathrm{p}=0.059$ ] and different study design [RCT: OR $=2.763,95 \% \mathrm{Cl}(2.188,3.489), \mathrm{I}^{2}=39.7 \%, \mathrm{z}=8.53, \mathrm{p}<0.001$; retrospective: $\mathrm{OR}=3.284,95 \% \mathrm{Cl}(1.359$, 7.934), $\left.I^{2}=64.0 \%, z=2.64, p=0.008\right]$. In the Asian group and the European group, the difference were statistically significant.

\section{Gene expression of ER, PR and HER2}

The lymphocyte-predominant breast cancer (LPBC) incidence rate in the ER $\square$ group was significantly lower than that in the ER-group [total: OR $\left.=0.291,95 \% \mathrm{Cl}(0.185,0.458), I^{2}=70.0 \%, z=5.35, p<0.001\right]$;After that, subgroup analysis were conducted on different ethnicity [Europe: $\mathrm{OR}=0.348,95 \% \mathrm{Cl}(0.197,0.614), \mathrm{I}^{2}=$ $61.1 \%, z=3.65, p<0.001$; Asia: OR = 0.154, 95\%Cl (0.090, 0.264), z = 6.80, p < 0.001; America: OR = 0.342, $95 \% \mathrm{Cl}(0.216,0.540), z=4.60, p<0.001]$ and different study design [RCT: OR $=0.360,95 \% \mathrm{Cl}(0.230$, $0.563), I^{2}=60.1 \%, z=4.49, p<0.001$; retrospective: $O R=0.191,95 \% C l(0.105,0.346), I^{2}=30.4 \%, z=5.44, p$ $<0.001$ ]. In addition, PR $\square$ and PR groups [total:OR $=0.396,95 \% \mathrm{Cl}(0.173,0.906), \mathrm{I}^{2}=0.0 \%, z=2.19, p=$ 0.028]. Furthermore, the detection rate of lymphocyte predominant breast cancer (LPBC) between HER2 group and HER2 $\$ group has not significant difference. [total: $\mathrm{OR}=1.359,95 \% \mathrm{Cl}(0.646,2.858), \mathrm{z}=0.81, \mathrm{p}$ $=0.419$ ] . different ethnicity [Europe: $\mathrm{OR}=1.443,95 \% \mathrm{Cl}(0.529,3.933), \mathrm{I}^{2}=92.0 \%, z=0.72, p=0.474$; Asia: OR $=1.097,95 \% \mathrm{Cl}(0.539,2.230), z=0.25, p=0.799]$.

\section{Ki-67 status}

The incidence of the lymphocyte-predominant breast cancer (LPBC) was significantly different between the high Ki-67 groups and the low Ki-67 groups (overall: $\mathrm{OR}=6.378,95 \% \mathrm{Cl}[3.674,11.073], \mathrm{I}^{2}=30.1 \%, \mathrm{z}=$ $6.58, \mathrm{p}<0.001)$.

\section{Menopausal status}


The lymphocyte-predominant breast cancer (LPBC) detection rate between the premenopausal group and the postmenopausal group has not significant difference [total: $\mathrm{OR}=0.963,95 \% \mathrm{Cl}(0.716,1.296), \mathrm{I}^{2}=0.0 \%$, $z=0.25, p=0.804$ ]. After that, subgroup analysis were conducted on different ethnicity [Asia: $O R=1.036$, $95 \% \mathrm{Cl}(0.629,1.708), \mathrm{l}^{2}=29.3 \%, \mathrm{z}=0.14, \mathrm{p}=0.888$; America: $\mathrm{OR}=0.874,95 \% \mathrm{Cl}(0.571,1.339), \mathrm{z}=0.62, \mathrm{p}$ $=0.537]$.

\section{TNM stage}

The lymphocyte-predominant breast cancer (LPBC) detection rate between the III, $\nabla$ group and I, II group has not significant difference [total: $\left.O R=0.825,95 \% \mathrm{Cl}(0.220,3.095), \mathrm{I}^{2}=81.4 \%, z=0.29, p=0.775\right]$. After that, subgroup analysis were conducted on ethnicity [Europe: $\mathrm{OR}=0.431,95 \% \mathrm{Cl}(0.211,0.881), \mathrm{I}^{2}=0.0 \%, \mathrm{z}$ $=2.31, p=0.021$; Asia: $\left.O R=1.268,95 \% \mathrm{Cl}(0.684,4.050), I^{2}=0.0 \%, z=1.12, p=0.261\right]$. The difference was statistically significant in the Europe group. The results of pooled analysis were summarized in Table 3 .

\section{Impact of TILs on pathological complete response (pCR)}

In order to further assess the predictive effect of TILs detection in breast cancer patients with different molecular subtypes, the OR value of PCR was analyzed by meta-analysis. In this meta-analysis, we chose those studies that focused on TILs as a continuous parameter (per 10\% increments). OR value of pCR were available in three studies including luminal molecular subtype breast cancer. There was no significant increase of PCR in high TILs group [OR $=1.154,95 \% \mathrm{Cl}(0.789-1.690), p=0.460]$. OR value of pCR were available in seven studies including HER2 enriched molecular subtype breast cancer. The assessed pooled OR value confirmed that high TILs was correlated with a significantly increased $\mathrm{PCR}$ [OR $=1.137,95 \% \mathrm{Cl}(1.061-1.218), \mathrm{p}<0.001]$. OR value of $\mathrm{pCR}$ were available in seven studies including TNBC molecular subtype breast cancer. The estimated pooled OR value showed that high TILs was related to significantly increased $p C R$ [OR $=1.120,95 \% \mathrm{Cl}(1.061-1.182), p<0.001]$. OR value of $p C R$ were available in nine studies including all breast cancer patients. The assessed pooled OR value confirmed that high TILs was related to significantly increased pCR [OR $=1.214,95 \% \mathrm{Cl}(1.108-1.329), p<0.001]$. High quality researches (NOS score $>6$ ) were used to perform the sensitivity analysis and the results were consistent (HER2 enriched molecular subtype breast cancer: $\mathrm{OR}=1.133,95 \% \mathrm{Cl} 1.057-1.215, \mathrm{P}<0.001$; TNBC molecular subtype breast cancer: $\mathrm{OR}=1.237,95 \% \mathrm{Cl} 1.094-1.399, \mathrm{P}=0.001)$. But in breast cancer patients with luminal molecular subtype, estimated pooled OR value showed that high TILs was correlated with significantly increased pCR [OR $=1.298,95 \% \mathrm{Cl}(1.157-1.456), \mathrm{p}<0.001]$. Figure 2 summarized the results of the PCR assessment. The publication bias was detected by Begg's test (Fig. 3).

\section{Effect of TILs on prognosis (OS and DFS)}

In order to further estimate the survival impact of TILs detection in breast cancer patients with different molecular subtypes, the HR value of DFS or OS was analyzed by meta-analysis. In this meta-analysis, we chose those studies that focused on TILs as a continuous parameter (per $10 \%$ increments). Four studies about luminal molecular subtype breast cancer provide HRs values of DFS. There was no significant improvement of DFS in high TILs group [HR $=0.998,95 \% \mathrm{Cl}(0.977-1.019), \mathrm{p}=0.840]$. Four studies about HER2 enriched molecular subtype breast cancer provide HRs values of DFS. The assessed pooled HRs 
value confirmed that high TILs was correlated with a significantly increased DFS [HR $=0.940,95 \% \mathrm{Cl}$ (0.903-0.979), $p=0.003$ ]. Six studies about TNBC molecular subtype breast cancer provide HRs values of DFS. The estimated pooled HRs value showed that high TILs was related to significantly increased DFS $[H R=0.907,95 \% \mathrm{Cl}(0.862-0.954), \mathrm{p}<0.001]$. Four studies about all breast cancer patients provide HRs values of DFS. The assessed pooled HRs value confirmed that high TILs was correlated with significantly increased DFS [HR $=0.988,95 \% \mathrm{Cl}(0.979-0.997), p=0.012]$. High quality researches (NOS score $>6$ ) were used to carry out the sensitivity analysis and the results were consistent (breast cancer with HER2 enriched molecular subtype: $\mathrm{HR}=0.946,95 \% \mathrm{Cl} 0.913 \sim 0.980, \mathrm{P}=0.002$; breast cancer with TNBC molecular subtype: $\mathrm{HR}=0.893,95 \% \mathrm{Cl} 0.867 \sim 0.921, \mathrm{P}<0.001$; breast cancer with luminal molecular subtype: $\mathrm{HR}=0.998,95 \% \mathrm{Cl} 0.977 \sim 1.019, \mathrm{P}=0.840$ ). Figure 4 summarized the results of the DFS assessment. The publication bias was detected by Begg's test. No significant publication bias was found (Fig. 5).

In addition, the HRs values of OS were obtained in four researches. The pooled analysis confirmed that the high TILs group of luminal molecular subtype breast cancer was significantly correlated with unfavorable OS $[\mathrm{HR}=1.077,95 \% \mathrm{Cl}(1.016 \sim 1.141), \mathrm{p}=0.012]$. By contrary, the HRs values of OS were obtained in three researches about HER2 enriched molecular subtype patients. The assessed pooled HRs value showed that high TILs was related to significantly favourable OS [HR $=0.910,95 \% \mathrm{Cl}(0.866-0.957)$, $p<0.001]$. The HRs values of OS were obtained in eight researches about breast cancer with TNBC molecular subtype. The evaluated pooled HRs value indicated that high TILs was correlated with significantly favourable OS [HR $=0.869,95 \% \mathrm{Cl}(0.836 \sim 0.904), \mathrm{p}<0.001]$. The HRs values of OS were obtained in four researches about all breast cancer patients. The estimated pooled HRs value confirmed that high TILs was correlated with significantly favourable OS [HR $=1.017,95 \% \mathrm{Cl}(0.983-1.052), p=$ 0.324]. High quality researches (NOS score $>6$ ) were applied to conduct the sensitivity analysis and the results were consistent. Figure 6 summarized the results of the OS assessment. The publication bias was tested by Begg's test. No significant publication bias was found (Fig. 7).

\section{Discussion}

Breast cancer is a highly heterogeneous disease of clinical process and molecular type. At present, standardized systemic therapy has significantly increased the survival of breast cancer, but metastasis and recurrence remain the determinants of death. Therefore, how to further reduce recurrence and metastasis is still the key issues in clinical practice. The complex interaction between the immune system and cancer cells plays a vital role in controlling and eradicating cancer[3]. A few decades ago, people noticed that the tumor microenvironment contained a variable number of lymphocytes, later called tumor infiltrating lymphocytes (TILs)[42]. Tumor-infiltrating lymphocytes (TILs) have become a potential biomarker for survival prediction of breast cancer patients $[4,5]$. In patients with different molecular subtypes, a wide evaluation of the clinical impact of TILs will help to discover the important mechanism of the interaction between tumor and host immunity. Nevertheless,the clinical significance of TILs in different molecular subtypes patients is still unclear. By summarizing and analyzing relevant high-quality 
researches, our meta-analysis aims to provide evidences for determining the clinical significance of TILs in different molecular subtypes breast cancer.

Pooled analysis confirmed that lymphocyte-predominant breast cancer (LPBC) was significantly correlated with higher histopathological grade. Moreover, our meta-analysis indicated that LPBC was related to Ki-67, ER and PR status. Afterwards, sensitivity analysis excluding low-quality researches showed consistent results. Whether TILs played different roles in patients with different molecular subtypes remains unknown. We further analyzed the prognostic value and predictive roles of TILs in different molecular subtypes patients. In order to further estimate the survival impact of TILs detection in patients with different molecular subtypes, the HR value of DFS or OS was analyzed by meta-analysis. The assessed pooled OR value confirmed that high TILs was correlated with significantly increased pCR in HER2 enriched molecular subtype breast cancer in multivariate analysis researches. The assessed pooled HRs value confirmed that high TILs was correlated with significantly increased DFS. The assessed pooled HRs value showed that high TILs was related to significantly favourable OS. The sensitivity analysis showed the robustness of the HR estimates.

In TNBC molecular subtype breast cancer, estimated pooled OR value showed that high TILs was related to significantly improved PCR in multivariate analysis researches. Furthermore, the assessed pooled HRs value confirmed that high TILs was correlated with significantly improved DFS and favourable OS in multivariate analysis researches.

In luminal molecular subtype breast cancer, there was no significant increase of PCR in high TILs group. In addition, there was no significant improvement of DFS in high TILs group. Conversely, the pooled analysis confirmed that high TILs group of luminal molecular subtype breast cancer was significantly correlated with unfavorable OS. Due to the small number of studies, the results of this analysis should be interpreted with caution.

Our meta-analysis confirmed that TILs is an ideal biomarker for TNBC molecular subtype and HER2 enriched molecular subtype breast cancer to predict pathological complete response and favourable prognosis. On the contrary, TILs is a biomarker for predicting poor overall survival of breast cancer with luminal molecular subtypes. Therefore, TILs should be monitored in breast cancer patients for rational stratification and adjusting the treatment strategy, and further detailed and in-depth researches on TILs and breast cancers of different molecular subtypes are needed. Further study on the different roles of different TILs subclasses in different molecular subtypes breast cancer will help us to further understand the precise mechanism of TILs and provide more evidences for immunotherapy of breast cancer with different molecular subtypes.

The limitations of this meta-analysis include the following aspects. Firstly, heterogeneity cannot be avoided completely, so we choose random effect model. Secondly, fewer high-quality stratified studies on different molecular subtypes of breast cancer can affect the statistical efficacy of our results. Therefore, it is necessary to conduct more prospective clinical studies to clarify the true usefulness of TILs. Thirdly, our study is according to data provided by different studies, not individual patient data, so reliable 
correlation estimates cannot be made. Although our research has some limitations, we systematically evaluated a large number of high-quality researches with multivariate analysis, and the research results may be a reliable reference for guiding clinical practice.

\section{Conclusion}

In conclusion, we performed a meta-analysis included thirty-three high quality studies including multivariate analysis and 18170 patients with different molecular subtypes breast cancer were analyzed. our meta-analysis confirms that high TILs is correlated with favourable survival and predicts pathological complete response in breast cancer patients with TNBC molecular subtypes and HER2-enriched molecular subtypes. Conversely, the pooled analysis confirmed that high TILs group of luminal molecular subtype breast cancer was significantly correlated with unfavorable OS. Large scale, multicenter and welldesigned high-quality studies are needed to study the role of different TILs subclasses in different molecular subtypes of breast cancer. Moreover, it can afford guidance for clinical practice of breast cancer with different molecular subtypes.

\section{Abbreviations}

TILs: tumor-infiltrating lymphocytes; sTILs: stromal tumor-infiltrating lymphocytes; iTILs: intratumoral tumor-infiltrating lymphocytes; OR: odds ratio; HR: hazard ratio; Cl: confidence intervals; pCR: pathologic complete response; DFS: disease-free survival; OS: overall survival; RFS: Relapse-free survival; BCSS: breast cancer-specific survival; DRFI: distant recurrence-free interval; MFS: metastases-free survival; DDFS: distant disease-free survival; BCFI: breast cancer-free interval; EFS: Event-free survival; HE: hematoxilin and eosin; IHC: Immunohistochemistry; CNB: core needle biopsy; NAC: Neoadjuvant chemotherapy; CRT: chemoradiotherapy; TMA: tissue microarrays; B-NC: before Neoadjuvant chemotherapy; post: postoperative; NR: Not reported; LN: lymph node; ER: estrogen receptor; PR: progesterone receptor; HER2: human epidermal growth factor receptor-2; TNBC: triple-negative breast cancer; LPBC: lymphocyte-predominant breast cancer; RCT: randomized controlled trial; NOS: NewcastleOttawa Scale.

\section{Declarations}

\section{Ethics approval and consent to participate}

The research was carried out according to the local regulations and was ratified by the Ethics Committee of the Liaoning Province Cancer Hospital and Research Institute.

\section{Consent for publication}

Consent for publication was obtained from the participants.

\section{Availability of data and material}


Not applicable

Competing interests

The authors declare that they have no competing interests.

Funding

None

Authors' contributions

Zhao-hua Gao, Ming Liu, and Cun-xin Li participated in the conception and design of the study. Zhao-hua Gao and Cun-xin Li participated in article selection and data extraction and provided statistical expertise. Zhao-hua Gao and Jia-yuan Jiang did the studies selection, data extraction, statistical analyses and the writing of report. Zhao-hua Gao and Ming Liu contributed to the literature search and figures. Zhao-hua Gao, Cun-xin Li, and Ming Liu participated in the critical revision of the manuscript and interpretation of data. All authors drafted and critically revised the manuscript and approved the final version.

\section{Acknowledgments}

We thank the department of Breast Surgery, Cancer Hospital of China Medical University and the department of Breast Surgery, Liaoning Cancer Hospital \& Institute for technical assistance.

\section{References}

1. Siegel R, Naishadham D, Jemal A: Cancer statistics, 2013. CA Cancer J Clin 2013, 63(1):11-30.

2. Jemal A, Bray F, Center MM, Ferlay J, Ward E, Forman D: Global cancer statistics. CA Cancer J Clin 2011, 61(2):69-90.

3. Pardoll DM: The blockade of immune checkpoints in cancer immunotherapy. Nat Rev Cancer 2012, 12(4):252-264.

4. Denkert C, Loibl S, Noske A, Roller M, Muller BM, Komor M, Budczies J, Darb-Esfahani S, Kronenwett $\mathrm{R}$, Hanusch $\mathrm{C}$ et al: Tumor-associated lymphocytes as an independent predictor of response to neoadjuvant chemotherapy in breast cancer. Journal of clinical oncology : official journal of the American Society of Clinical Oncology 2010, 28(1):105-113.

5. Loi S, Sirtaine N, Piette F, Salgado R, Viale G, Van Eenoo F, Rouas G, Francis P, Crown JP, Hitre E et al: Prognostic and predictive value of tumor-infiltrating lymphocytes in a phase III randomized adjuvant breast cancer trial in node-positive breast cancer comparing the addition of docetaxel to doxorubicin with doxorubicin-based chemotherapy: BIG 02-98. Journal of clinical oncology : official journal of the American Society of Clinical Oncology 2013, 31(7):860-867.

6. Higgins J GS: Cochrane Handbook for Systematic Reviews of Interventions Version 5.1.0 [updated March 2011]. The Cochrane Collaboration 2011: Available from wwwcochrane-handbookorg. 
7. Stang A: Critical evaluation of the Newcastle-Ottawa scale for the assessment of the quality of nonrandomized studies in meta-analyses. Eur J Epidemiol 2010, 25(9):603-605.

8. Tierney JF, Stewart LA, Ghersi D, Burdett S, Sydes MR: Practical methods for incorporating summary time-to-event data into meta-analysis. Trials 2007, 8:16.

9. Higgins JP, Thompson SG, Deeks JJ, Altman DG: Measuring inconsistency in meta-analyses. Bmj 2003, 327(7414):557-560.

10. Moher D, Liberati A, Tetzlaff J, Altman DG: Preferred reporting items for systematic reviews and meta-analyses: the PRISMA statement. PLoS Med 2009, 6(7):e1000097.

11. Hwang HW, Jung H, Hyeon J, Park YH, Ahn JS, Im YH, Nam SJ, Kim SW, Lee JE, Yu JH et al: A nomogram to predict pathologic complete response (PCR) and the value of tumor-infiltrating lymphocytes (TILs) for prediction of response to neoadjuvant chemotherapy (NAC) in breast cancer patients. Breast Cancer Res Treat 2019, 173(2):255-266.

12. Ahn SG, Cha YJ, Bae SJ, Yoon C, Lee HW, Jeong J: Comparisons of tumor-infiltrating lymphocyte levels and the 21-gene recurrence score in ER-positive/HER2-negative breast cancer. BMC cancer 2018, 18(1):320.

13. Yang X, Rao J, Yang W, Shui R: Evaluation of the Predictive and Prognostic Values of Stromal TumorInfiltrating Lymphocytes in HER2-Positive Breast Cancers treated with neoadjuvant chemotherapy. Targeted Oncology 2018, 13(6):757-767.

14. Herrero-Vicent C, Guerrero A, Gavila J, Gozalbo F, Hernandez A, Sandiego S, Algarra MA, Calatrava A, Guillem-Porta V, Ruiz-Simon A: Predictive and prognostic impact of tumour-infiltrating lymphocytes in triple-negative breast cancer treated with neoadjuvant chemotherapy. Ecancermedicalscience 2017, 11:759.

15. Luen SJ, Salgado R, Dieci MV, Vingiani A, Curigliano G, Gould RE, Castaneda C, D’Alfonso T, Sanchez $\mathrm{J}$, Cheng $\mathrm{E}$ et al: Prognostic implications of residual disease tumor-infiltrating lymphocytes and residual cancer burden in triple-negative breast cancer patients after neoadjuvant chemotherapy. Annals of Oncology 2019, 30(2):236-242.

16. Fujimoto Y, Watanabe T, Hida Al, Higuchi T, Miyagawa Y, Ozawa H, Bun A, Fukui R, Sata A, Imamura $\mathrm{M}$ et al: Prognostic significance of tumor-infiltrating lymphocytes may differ depending on Ki67 expression levels in estrogen receptor-positive/HER2-negative operated breast cancers. Breast cancer (Tokyo, Japan) 2019, 26(6):738-747.

17. Adams S, Gray RJ, Demaria S, Goldstein L, Perez EA, Shulman LN, Martino S, Wang M, Jones VE, Saphner TJ et al: Prognostic value of tumor-infiltrating lymphocytes in triple-negative breast cancers from two phase III randomized adjuvant breast cancer trials: ECOG 2197 and ECOG 1199. Journal of clinical oncology : official journal of the American Society of Clinical Oncology 2014, 32(27):29592966.

18. Dieci MV, Criscitiello C, Goubar A, Viale G, Conte P, Guarneri V, Ficarra G, Mathieu MC, Delaloge S, Curigliano $\mathrm{G}$ et al: Prognostic value of tumor-infiltrating lymphocytes on residual disease after 
primary chemotherapy for triple-negative breast cancer: a retrospective multicenter study. Annals of Oncology 2014, 25(3):611-618.

19. Perez EA, Ballman KV, Tenner KS, Thompson EA, Badve SS, Bailey H, Baehner FL: Association of Stromal Tumor-Infiltrating Lymphocytes With Recurrence-Free Survival in the N9831 Adjuvant Trial in Patients With Early-Stage HER2-Positive Breast Cancer. JAMA oncology 2016, 2(1):56-64.

20. Dieci MV, Mathieu MC, Guarneri V, Conte P, Delaloge S, Andre F, Goubar A: Prognostic and predictive value of tumor-infiltrating lymphocytes in two phase III randomized adjuvant breast cancer trials. Annals of oncology : official journal of the European Society for Medical Oncology 2015, 26(8):16981704.

21. Loi S, Michiels S, Salgado R, Sirtaine N, Jose V, Fumagalli D, Kellokumpu-Lehtinen PL, Bono P, Kataja $\mathrm{V}$, Desmedt $\mathrm{C}$ et al: Tumor infiltrating lymphocytes are prognostic in triple negative breast cancer and predictive for trastuzumab benefit in early breast cancer: results from the FinHER trial. Annals of oncology : official journal of the European Society for Medical Oncology 2014, 25(8):1544-1550.

22. Issa-Nummer Y, Darb-Esfahani S, Loibl S, Kunz G, Nekljudova V, Schrader I, Sinn BV, Ulmer HU, Kronenwett $\mathrm{R}$, Just $\mathrm{M}$ et al: Prospective validation of immunological infiltrate for prediction of response to neoadjuvant chemotherapy in HER2-negative breast cancer-a substudy of the neoadjuvant GeparQuinto trial. PLoS ONE 2013, 8(12):e79775.

23. Denkert C, von Minckwitz G, Brase JC, Sinn BV, Gade S, Kronenwett R, Pfitzner BM, Salat C, Loi S, Schmitt WD et al: Tumor-infiltrating lymphocytes and response to neoadjuvant chemotherapy with or without carboplatin in human epidermal growth factor receptor 2-positive and triple-negative primary breast cancers. Journal of clinical oncology : official journal of the American Society of Clinical Oncology 2015, 33(9):983-991.

24. Pruneri G, Gray KP, Vingiani A, Viale G, Curigliano G, Criscitiello C, Lang I, Ruhstaller T, Gianni L, Goldhirsch A et al: Tumor-infiltrating lymphocytes (TILs) are a powerful prognostic marker in patients with triple-negative breast cancer enrolled in the IBCSG phase III randomized clinical trial 22-00. Breast Cancer Res Treat 2016, 158(2):323-331.

25. Ingold Heppner B, Untch M, Denkert C, Pfitzner BM, Lederer B, Schmitt W, Eidtmann H, Fasching PA, Tesch $\mathrm{H}$, Solbach $\mathrm{C}$ et al: Tumor-Infiltrating Lymphocytes: A Predictive and Prognostic Biomarker in Neoadjuvant-Treated HER2-Positive Breast Cancer. Clinical cancer research : an official journal of the American Association for Cancer Research 2016, 22(23):5747-5754.

26. Denkert C, von Minckwitz G, Darb-Esfahani S, Lederer B, Heppner BI, Weber KE, Budczies J, Huober J, Klauschen F, Furlanetto $\mathrm{J}$ et al: Tumour-infiltrating lymphocytes and prognosis in different subtypes of breast cancer: a pooled analysis of $\mathbf{3 7 7 1}$ patients treated with neoadjuvant therapy. The Lancet Oncology 2018, 19(1):40-50.

27. Wang Q, Xiang Q, Yu L, Hu T, Chen Y, Wang J, Nie X, Cheng J: Changes in Tumor-Infiltrating Lymphocytes and Vascular Normalization in Breast Cancer Patients After Neoadjuvant Chemotherapy and Their Correlations With DFS. Frontiers In Oncology 2020, 9. 
28. Brodsky AS, Xiong J, Yang D, Schorl C, Fenton MA, Graves TA, Sikov WM, Resnick MB, Wang Y: Identification of stromal ColXa1 and tumor-infiltrating lymphocytes as putative predictive markers of neoadjuvant therapy in estrogen receptor-positive/HER2-positive breast cancer. BMC cancer 2016, 16(1).

29. Leon-Ferre RA, Polley MY, Liu H, Gilbert JA, Cafourek V, Hillman DW, Elkhanany A, Akinhanmi M, Lilyquist J, Thomas A et al: Impact of histopathology, tumor-infiltrating lymphocytes, and adjuvant chemotherapy on prognosis of triple-negative breast cancer. Breast Cancer Res Treat 2018, 167(1):89-99.

30. Salgado R, Denkert C, Campbell C, Savas P, Nuciforo P, Aura C, de Azambuja E, Eidtmann H, Ellis CE, Baselga $\mathrm{J}$ et al: Tumor-Infiltrating Lymphocytes and Associations With Pathological Complete Response and Event-Free Survival in HER2-Positive Early-Stage Breast Cancer Treated With Lapatinib and Trastuzumab: A Secondary Analysis of the NeoALTTO Trial. JAMA oncology 2015, 1(4):448-454.

31. Ignatiadis M, Van den Eynden G, Roberto S, Fornili M, Bareche Y, Desmedt C, Rothé F, Maetens M, Venet $\mathrm{D}$, Holgado $\mathrm{E}$ et al: Tumor-Infiltrating Lymphocytes in Patients Receiving Trastuzumab/Pertuzumab-Based Chemotherapy: A TRYPHAENA Substudy. JNCl: Journal of the National Cancer Institute 2019, 111(1):69-77.

32. Mori H, Kubo M, Yamaguchi R, Nishimura R, Osako T, Arima N, Okumura Y, Okido M, Yamada M, Kai $\mathrm{M}$ et al: The combination of PD-L1 expression and decreased tumorinfiltrating lymphocytes is associated with a poor prognosis in triple-negative breast cancer. Oncotarget 2017, 8(9):1558415592.

33. Dieci MV, Prat A, Tagliafico E, Pare L, Ficarra G, Bisagni G, Piacentini F, Generali DG, Conte P, Guarneri V: Integrated evaluation of PAM50 subtypes and immune modulation of pCR in HER2-positive breast cancer patients treated with chemotherapy and HER2-targeted agents in the CherLOB trial. Annals of oncology : official journal of the European Society for Medical Oncology 2016, 27(10):1867-1873.

34. Ruan M, Tian T, Rao J, Xu X, Yu B, Yang W, Shui R: Predictive value of tumor-infiltrating lymphocytes to pathological complete response in neoadjuvant treated triple-negative breast cancers. Diagnostic Pathology 2018, 13(1).

35. O'Loughlin M, Andreu X, Bianchi S, Chemielik E, Cordoba A, Cserni G, Figueiredo P, Floris G, Foschini MP, Heikkilä $P$ et al: Reproducibility and predictive value of scoring stromal tumour infiltrating lymphocytes in triple-negative breast cancer: a multi-institutional study. Breast Cancer Research and Treatment 2018, 171(1):1-9.

36. Ali HR, Dariush A, Provenzano E, Bardwell H, Abraham JE, Iddawela M, Vallier A-L, Hiller L, Dunn JA, Bowden SJ et al: Computational pathology of pre-treatment biopsies identifies lymphocyte density as a predictor of response to neoadjuvant chemotherapy in breast cancer. Breast Cancer Research 2016, 18(1).

37. Song IH, Heo SH, Bang WS, Park HS, Park IA, Kim YA, Park SY, Roh J, Gong G, Lee HJ: Predictive Value of Tertiary Lymphoid Structures Assessed by High Endothelial Venule Counts in the 
Neoadjuvant Setting of Triple-Negative Breast Cancer. Cancer research and treatment : official journal of Korean Cancer Association 2017, 49(2):399-407.

38. Li X, Krishnamurti U, Bhattarai S, Klimov S, Reid MD, O'Regan R, Aneja R: Biomarkers Predicting pathologic complete response to neoadjuvant chemotherapy in breast cancer. American Journal of Clinical Pathology 2016, 145(6):871-878.

39. Würfel F, Erber R, Huebner H, Hein A, Lux MP, Jud S, Kremer A, Kranich H, Mackensen A, Häberle L et al: TILGen: A Program to Investigate Immune Targets in Breast Cancer Patients-First Results on the Influence of Tumor-Infiltrating Lymphocytes. Breast Care 2018, 13(1):8-14.

40. Hamy AS, Bonsang-Kitzis H, De Croze D, Laas E, Darrigues L, Topciu L, Menet E, Vincent-Salomon A, Lerebours F, Pierga JY et al: Interaction between Molecular Subtypes and Stromal Immune Infiltration before and after Treatment in Breast Cancer Patients Treated with Neoadjuvant Chemotherapy. Clinical cancer research : an official journal of the American Association for Cancer Research 2019, 25(22):6731-6741.

41. Khoury T, Nagrale V, Opyrchal M, Peng X, Wang D, Yao S: Prognostic Significance of Stromal Versus Intratumoral Infiltrating Lymphocytes in Different Subtypes of Breast Cancer Treated with Cytotoxic Neoadjuvant Chemotherapy. Applied Immunohistochemistry and Molecular Morphology 2018, 26(8):523-532.

42. Moore OS, Jr., Foote FW, Jr.: The relatively favorable prognosis of medullary carcinoma of the breast. Cancer 1949, 2(4):635-642.

\section{Tables}


Tab le 1. Baseline characteristics of included studies

\begin{tabular}{|c|c|c|c|c|c|c|c|c|c|c|c|}
\hline first a uthor & $\begin{array}{c}\text { year of } \\
\text { publication }\end{array}$ & Country & Study design & $\begin{array}{l}\text { Number } \\
\text { (n) }\end{array}$ & $\begin{array}{c}\text { Treatment } \\
\text { type }\end{array}$ & sample time & TIL s site & $\begin{array}{c}\text { TIL } \\
\text { ex aluation } \\
\text { method }\end{array}$ & $\begin{array}{l}\text { curative } \\
\text { resection }\end{array}$ & $\begin{array}{l}\text { Endpoint } \\
\text { mea sured }\end{array}$ & $\begin{array}{c}\text { Follow up } \\
\text { Median } \\
\text { (range)(M) }\end{array}$ \\
\hline $\begin{array}{c}\text { Hwang Hye } \\
\text { Won }\end{array}$ & 2019 & Korea & retrospective & 308 & NAC & $\begin{array}{c}\text { pre-NAC/post- } \\
\text { NAC }\end{array}$ & sTILs & $\mathrm{HE}$ & YES & $\begin{array}{c}\text { pCRDFS/ } \\
\text { BCSS }\end{array}$ & 60.1 \\
\hline Ahn, S. G. ${ }^{12}$ & 2018 & Korea & retrospective & 198 & not NAC & resection tissue & sTILs & $\mathrm{HE}$ & NR & No & NR \\
\hline $\mathrm{Yang} \mathrm{Xia}^{12}$ & 2018 & China & retrospective & 143 & $\mathrm{NAC}+\mathrm{H}$ & $\begin{array}{c}\text { pre-NAC/post- } \\
\text { NAC }\end{array}$ & sTILs & $\mathrm{HE}$ & YES & $\begin{array}{c}\text { pCRDFS } / \\
\text { OS }\end{array}$ & $53(12-102)$ \\
\hline $\begin{array}{c}\text { Herrero- } \\
\text { Vicent. C. }{ }^{14}\end{array}$ & 2017 & Spain & retrospective & 164 & NAC & $\begin{array}{c}\text { pre-NAC/post- } \\
\text { NAC }\end{array}$ & sTIL s & $\mathrm{HE}$ & $\mathrm{NR}$ & pCR/DFS & 78 \\
\hline Luen, S. J. ${ }^{15}$ & 2019 & Australia & retrospective & 375 & NAC & $\begin{array}{c}\text { pre-NAC/post- } \\
\text { NAC }\end{array}$ & sTILs & $\mathrm{HE}$ & $\mathrm{NR}$ & RFS/OS & 72 \\
\hline $\begin{array}{l}\text { Fujim oto, } \\
\text { Yukie }^{16}\end{array}$ & 2019 & Japan & retrospective & 717 & NAC/adjuvant & $\begin{array}{c}\text { pre-NAC/post- } \\
\text { NAC }\end{array}$ & iTIL stsTIL $s$ & $\mathrm{HE}$ & YES & DFS/OS & $35.1(1-100.6)$ \\
\hline Adams, S. ${ }^{17}$ & 2014 & USA & RCT & 481 & adjuvant & resection tissue & iTIL stsTIL & $\mathrm{HE}$ & $\mathrm{NR}$ & $\begin{array}{c}\text { DFS/OS/D } \\
\text { RFI }\end{array}$ & 127.2 \\
\hline Dieci, M V. ${ }^{18}$ & 2014 & France/Italy & retrospective & 278 & NAC/adjuvant & post-NAC & iTIL s+sTIL s & $\mathrm{HE}$ & NR & MFS/OS & 75.6 \\
\hline Perez, E. A. ${ }^{10}$ & 2016 & USA & RCT & 945 & adjuvant & resection tissue & sTIL s & $\mathrm{HE}$ & NR & RFS & 52.8 \\
\hline Dieci, M V. ${ }^{20}$ & 2015 & France & $\mathrm{RCT}$ & 781 & adjuvant & resection tissue & iTIL stsTIL s & $\mathrm{HE}$ & NR & OS/DFS & 152.4 \\
\hline Loi. S. ${ }^{5}$ & 2013 & B el gium & $\mathrm{RCT}$ & 2009 & adjuvant & resection tissue & iTIL stsTLs & $\mathrm{HE}$ & NR & DFS/OS & 96 \\
\hline Loi, S. ${ }^{21}$ & 2014 & Finnish & retrospective & 934 & adjuvant & resection tissue & sTILs & $\mathrm{HE}$ & NR & DDFS/OS & 62 \\
\hline $\begin{array}{l}\text { Yasmin Issa- } \\
\text { Nummer }\end{array}$ & 2013 & Germany & RCT & 313 & NAC & pre-NAC & iTIL s+sTILs & $\mathrm{HE}$ & NR & $\mathrm{pCR}$ & NR \\
\hline Denkert. C. ${ }^{4}$ & 2010 & Germ any & RCT & 1058 & NAC & pre-NAC & iTIL stsTILs & $\mathrm{HE}$ & NR & $\mathrm{pCR}$ & NR \\
\hline Denkert, C. ${ }^{22}$ & 2015 & Germany & RCT & 580 & NAC & pre-NAC & iTIL stsTIL s & $\mathrm{HE}$ & NR & $\mathrm{pCR}$ & NR \\
\hline Pruneri, G. ${ }^{24}$ & 2016 & Italy & RCT & 647 & adjuvant & resection tissue & sTILs & $\mathrm{HE}$ & NR & $\begin{array}{c}\text { BCFI / } \\
\text { DFS / } \\
\text { DRFI / OS }\end{array}$ & 82.8 \\
\hline $\begin{array}{c}\text { Ingold } \\
\text { Heppner, B. }\end{array}$ & 2016 & Germany & RCT & 498 & NAC & pre-NAC & sTILs & $\mathrm{HE}$ & NR & $\mathrm{pCR} / \mathrm{DFS}$ & $\begin{array}{c}60.4(59.5- \\
61.3)\end{array}$ \\
\hline Denkert, C. ${ }^{26}$ & 2018 & Germany & $\mathrm{RCT}$ & 3771 & NAC & pre-NAC & sTILs & $\mathrm{HE}$ & $\mathrm{NR}$ & $\begin{array}{c}\mathrm{pCR} / \mathrm{DFS} \\
/ \mathrm{OS}\end{array}$ & 62.8 \\
\hline Wang Qiong ${ }^{27}$ & 2020 & China & retrospective & 75 & NAC & $\begin{array}{c}\text { pre-NAC/post- } \\
\text { NAC }\end{array}$ & sTILs & $\mathrm{HE} / \mathbb{H C}$ & YES & $\mathrm{pCR} / \mathrm{DFS}$ & $23.2(6.1-64.5)$ \\
\hline $\begin{array}{c}\text { Brodsky, } \\
\text { Alexander S. }\end{array}$ & 2016 & USA & retrospective & 50 & $\mathrm{NAC}+\mathrm{H}$ & pre-NAC & sTILs & $\mathrm{HE}$ & $\mathrm{NR}$ & $\mathrm{pCR}$ & 127.2 \\
\hline $\begin{array}{l}\text { Leon-Ferre, } \\
\text { Roberto } A^{20}\end{array}$ & 2018 & USA & retrospective & 605 & adjuvant & resection tissue & iTIL stsTIL $s$ & $\mathrm{HE}$ & YES & IDFS / OS & 127.2 \\
\hline $\begin{array}{l}\text { Salgado, } \\
\text { Roberto }\end{array}$ & 2015 & Australia & $\mathrm{RCT}$ & 387 & $\mathrm{NAC}+\mathrm{H} / \mathrm{L}$ & pre-NAC & sTILs & $\mathrm{HE}$ & $\mathrm{NR}$ & $\mathrm{EFS} / \mathrm{pCR}$ & $45.2(42-50.6)$ \\
\hline $\begin{array}{l}\text { Ignatiadis, } \\
\text { Michail }^{31}\end{array}$ & 2019 & B el givum & RCT & 213 & NAC & $\begin{array}{c}\text { pre-NAC/post- } \\
\text { NAC }\end{array}$ & sTILs & $\mathrm{HE}$ & NR & $\mathrm{pCR} / \mathrm{EFS}$ & 56.4 \\
\hline Mori. $\mathrm{H}^{21}$ & 2017 & Japan & retrospective & 248 & adjuvant & resection tissue & sTILs & $\mathrm{HE}$ & YES & RFS / OS & $68(2-150)$ \\
\hline Dieci, M V. ${ }^{23}$ & 2016 & Italy & retrospective & 105 & NAC & $\begin{array}{c}\text { pre-NAC/post- } \\
\text { NAC }\end{array}$ & iTIL stsTIL s & $\mathrm{HE}$ & YES & pCR / EFS & $\mathrm{NR}$ \\
\hline Ruan, $\mathrm{MaO}^{34}$ & 2018 & China & retrospective & 166 & NAC & pre-NAC & iTIL stsTILs & $\mathrm{HE}$ & YES & pCR & NR \\
\hline $\begin{array}{l}\text { O' Loughlin, } \\
\text { Mark }^{25}\end{array}$ & 2018 & Irel and & retrospective & 75 & NAC & pre-NAC & sTIIs & $\mathrm{HE}$ & $\mathrm{NR}$ & $\mathrm{pCR}$ & $\mathrm{NR}$ \\
\hline$A 1 i$, H. Raza ${ }^{26}$ & 2016 & UK & RCT & 614 & NAC & $\begin{array}{c}\text { pre-NAC/post- } \\
\text { NAC }\end{array}$ & sTIL s & $\mathrm{HE}$ & $\mathrm{NR}$ & $\mathrm{pCR}$ & NR \\
\hline Song I. $\mathrm{H}^{27}$ & 2017 & Korea & retrospective & 108 & NAC & $\begin{array}{c}\text { pre-NAC/post- } \\
\text { NAC }\end{array}$ & sTILs & $\mathrm{HE} / \mathbb{H C C}$ & YES & pCRDFS & $31.4(21.1-53.0)$ \\
\hline Li. $\mathrm{X}^{28}$ & 2016 & USA & retrospective & 129 & $\mathrm{NAC}+\mathrm{H}$ & pre-NAC & iTIL stsTL s & $\mathrm{HE}$ & YES & $\mathrm{pCR}$ & $\mathrm{NR}$ \\
\hline Würfel. F. & 2018 & Germany & retrospective & 146 & NAC & pre-NAC & sTILs & $\mathrm{HE}$ & NR & $\mathrm{pCR}$ & NR \\
\hline Hamy, A. S. ${ }^{40}$ & 2019 & France & retrospective & 718 & $\mathrm{NAC} \pm \mathrm{H}$ & $\begin{array}{c}\text { pre-NAC/post- } \\
\text { NAC }\end{array}$ & sTIL s & $\mathrm{HE}$ & YES & $\begin{array}{c}\text { pCRDFS/ } \\
\text { OS }\end{array}$ & $\mathrm{NR}$ \\
\hline Khoury, $T^{41}$ & 2018 & USA & retrospective & 331 & NAC & pre-NAC & iTIL stsTIL s & $\mathrm{HE}$ & NR & $\mathrm{pCR}$ & $\mathrm{NR}$ \\
\hline
\end{tabular}


Table 2. The evaluation of the risk of bias in research using the Newcastle-Ottaw a scale Study Selection (0-4) Comparability (0-2) Outcome (0-3)

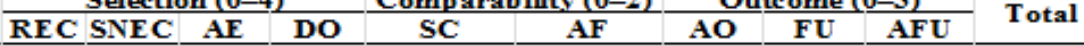

Hwang, Hye Won et

al. ${ }^{1}$

Ahn, S. G et al. ${ }^{12}$

$\mathrm{Y}$ ang, $\mathrm{Xi}$ a et al. ${ }^{13}$

Herrero-Vicent, $\mathrm{C}$ et al. $^{14}$

Luen, S. J et al. ${ }^{15}$

Fujimoto, Yukie et al. ${ }^{16}$

Adams, $S$ et al. ${ }^{17}$

Dieci, M. V et a1. $2014^{18}$

Perez, E. A et al. ${ }^{10}$

Dieci, M. $\mathrm{V}$ et al. $2015^{20}$

Loi, $\mathrm{S}$ et al. $2013^{5}$

Loi, $\mathrm{S}$ et al. $2014^{21}$

Yasmin Issa-Nummer et al. ${ }^{22}$

Denkert, C et 1

a1. $2010^{4}$

Denkert,

al. $2015^{23}$

Pruneri, G et al. ${ }^{24}$

Ingold Heppner, B et al. $^{2} s$

Denkert, C a1. $2018^{26}$

Wang, Qiong et al. ${ }^{27}$

Brodsky, Alexander S et al. ${ }^{28}$

Leon-Ferre, Roberto

A et al. 20

Salgado, Roberto et al. $^{30}$

Ignatiadis, Michail et al. $^{31}$

Mori, $\mathrm{H}$ et al. ${ }^{32}$ al. $2016^{33}$

Ruan, Miao et al. ${ }^{34}$

O'Loughlin, Mark et al. $^{3 s}$

Ali, H. Raza et al. ${ }^{36}$

Song. I. H et al. ${ }^{37}$

Li, $\mathrm{X}$ et al. ${ }^{38}$

Würfel, F et al. 30

Harmy, A. S et al. 40

Khoury, T et al. ${ }^{41}$

NOTE: REC: Representativeness of the exposed cohort; SNEC: Selection of the non exposed cohort; AE: A scertainment of exposure; DO: Demonstration that outcome of interest was not present at start of study; SC: study controls for age, sex; AF: study controls for any additional factor, AO: A ssessment of outcome; FU:

follow-up long enough for outcomes to occux (36 Months); AFU: Adequacy of follow up of cohorts ( $\geqslant 90 \%$ ).

" 1 " me ans that the study is meeted the item and " 0 " means the opposite situration. 
Table 3. Detailed subgroup analysis of clinicopathological parameters

\begin{tabular}{|c|c|c|c|c|c|c|}
\hline \multirow{2}{*}{$\begin{array}{l}\text { clinicopathologic } \\
\text { al parameters }\end{array}$} & \multirow[b]{2}{*}{ Any } & \multicolumn{3}{|c|}{ Different ethnicity } & \multicolumn{2}{|c|}{ Different study design } \\
\hline & & Europe & Asia & America & RCT & Retrospective \\
\hline $\begin{array}{l}\text { Age }>50 \text { vs. } \leqslant 50 \\
(\mathrm{OR})\end{array}$ & $\begin{array}{l}0.873[0.761,1.002] ; \\
\mathrm{I} 2=0.0 \% ; \mathrm{z}=1.93 ; \mathrm{p} \\
=0.054\end{array}$ & $\begin{array}{l}0.868[0.754,1.000] \\
\mathrm{I} 2=0.0 \% ; \mathrm{z}=1.96 ; \mathrm{p} \\
=0.049\end{array}$ & $\begin{array}{l}0.990[0.513,1.912] \\
z=0.03 ; p=0.976\end{array}$ & - & $\begin{array}{l}0.869[0.753,1.002] \\
\mathrm{I} 2=0.0 \% ; z=1.93 ; \\
\mathrm{p}=0.054\end{array}$ & $\begin{array}{l}0.935[0.563,1.554] \\
\mathrm{I} 2=0.0 \% ; \mathrm{z}=0.26 ; \mathrm{p} \\
=0.795\end{array}$ \\
\hline $\begin{array}{l}\text { pT:T3/T4 } \\
\text { vs.T1/T2 (OR) }\end{array}$ & $\begin{array}{l}0.646[0.542,0.771] \\
I 2=0.0 \% \% ; z=4.85 ; \\
p<0.001\end{array}$ & $\begin{array}{l}0.661[0.546,0.800] ; \\
\mathrm{I} 2=0.0 \% ; \mathrm{z}=4.25 ; \mathrm{p} \\
<0.001\end{array}$ & $\begin{array}{l}0.516[0.297,0.898] \\
\mathrm{I} 2=0.0 \% ; \mathrm{z}=2.34 ; \mathrm{p} \\
=0.019\end{array}$ & $\begin{array}{l}0.695[0.294,1.643] \\
z=0.83 ; p=0.407\end{array}$ & $\begin{array}{l}0.663[0.550,0.798] \\
\mathrm{I} 2=0.0 \% ; \mathrm{z}=4.33 ; \mathrm{p} \\
<0.001\end{array}$ & $\begin{array}{l}0.516[0.297,0.898] \\
\mathrm{I} 2=0.0 \% ; \mathrm{z}=2.34 ; \mathrm{p} \\
=0.019\end{array}$ \\
\hline $\begin{array}{l}\mathrm{LN}(+) \text { vs. LN(- } \\
)(\mathrm{OR})\end{array}$ & $\begin{array}{l}0.941[0.681 \\
1.298] ; \mathrm{I} 2=76.4 \% \\
z=0.37 ; p=0.709\end{array}$ & $\begin{array}{l}0.991[0.633,1.551] \\
\mathrm{I} 2=80.8 \% ; \mathrm{z}=0.04 ; \mathrm{p} \\
=0.968\end{array}$ & $\begin{array}{l}1.013[0.595 \\
1.726] ; \mathrm{I} 2=60.8 \% \\
z=0.05 ; p=0.962\end{array}$ & $\begin{array}{l}0.549[0.322,0.936] \\
z=2.20 ; p=0.028\end{array}$ & $\begin{array}{l}1.003[0.651,1.546] \\
\mathrm{I} 2=82.4 \% ; z=0.01 ; \\
\mathrm{p}=0.989\end{array}$ & $\begin{array}{l}0.858[0.501,1.468] \\
\mathrm{I} 2=66.5 \% ; \mathrm{z}=0.56 ; \mathrm{p} \\
=0.576\end{array}$ \\
\hline IDC vs. $\amalg C(O R)$ & $\begin{array}{l}2.654[1.132 \\
, 6.223] ; \mathrm{I} 2=68.0 \% \\
\mathrm{z}=2.24 ; \mathrm{p}=0.025\end{array}$ & $\begin{array}{l}2.642[0.700,9.967] \\
\mathrm{I} 2=84.0 \% ; z=1.43 ; \\
\mathrm{p}=0.152\end{array}$ & $\begin{array}{l}2.883[0.766 \\
, 10.85] ; \mathrm{I} 2=0.0 \% \\
z=1.57 ; \mathrm{p}=0.118\end{array}$ & $\begin{array}{l}2.571[0.614,10.77] \\
z=1.29 ; p=0.196\end{array}$ & $\begin{array}{l}4.735[2.850,7.867] \\
\mathrm{I} 2=0.0 \% ; \mathrm{z}=6.00 ; \mathrm{p} \\
<0.001\end{array}$ & $\begin{array}{l}1.101[0.622,1.951] \\
\mathrm{I} 2=0.0 \% ; \mathrm{z}=0.33 ; \mathrm{p} \\
=0.740\end{array}$ \\
\hline $\begin{array}{l}\text { Histological } \\
\text { grade:III vs.I- } \\
\mathrm{II}(\mathrm{OR})\end{array}$ & $\begin{array}{l}2.889[2.218,3.762 \\
] ; \mathrm{I} 2=49.5 \% ; \\
z=7.87 ; p<0.001\end{array}$ & $\begin{array}{l}2.871[2.290,3.600] ; \\
\mathrm{I} 2=25.5 \% ; \mathrm{z}=9.14 ; \mathrm{p} \\
<0.001\end{array}$ & $\begin{array}{l}5.636[3.050 \\
, 10.42] ; \mathrm{I} 2=0.0 \% \\
z=5.52 ; p<0.001\end{array}$ & $\begin{array}{l}1.659[0.982,2.804] \\
z=1.89 ; p=0.059\end{array}$ & $\begin{array}{l}2.763[2.188,3.489] \\
\mathrm{I} 2=39.7 \% ; z=8.53 ; \\
\mathrm{p}<0.001\end{array}$ & $\begin{array}{l}3.284[1.359,7.934] \\
\mathrm{I} 2=64.0 \% ; \mathrm{z}=2.64 ; \mathrm{p} \\
=0.008\end{array}$ \\
\hline ER $(+)$ vs.(-) (OR) & $\begin{array}{l}0.291[0.185,0.458] \\
\mathrm{I} 2=70.0 \% ; z=5.35 \\
<0.001\end{array}$ & $\begin{array}{l}0.348[0.197,0.614] \\
\mathrm{I} 2=61.1 \% ; \mathrm{z}=3.65 \\
\mathrm{p}<0.001\end{array}$ & $\begin{array}{l}0.154[0.090,0.264] \\
z=6.80 ; p<0.001\end{array}$ & $\begin{array}{l}0.342[0.216,0.540] \\
z=4.60 ; p<0.001\end{array}$ & $\begin{array}{l}0.360[0.230,0.563] \\
\mathrm{I} 2=60.1 \% ; z=4.49 \\
\mathrm{p}<0.001\end{array}$ & $\begin{array}{l}0.191[0.105,0.346] \\
\mathrm{I} 2=30.4 \% ; z=5.44 ; \\
\mathrm{p}<0.001\end{array}$ \\
\hline PR (+) vs.(-) (OR) & $\begin{array}{l}0.396[0.173,0.906] \\
\mathrm{I} 2=0.0 \% ; z=2.19 ; \\
p=0.028\end{array}$ & - & - & - & - & - \\
\hline $\begin{array}{l}\text { HER2 (+) vs.(-) } \\
(\mathrm{OR})\end{array}$ & $\begin{array}{l}1.359[0.646,2.858] \\
\mathrm{I} 2=88.0 \% ; z=0.81 ; \\
\mathrm{p}=0.419\end{array}$ & $\begin{array}{l}1.443[0.529,3.933] \\
\mathrm{I} 2=92.0 \% ; z=0.72 ; \\
\mathrm{p}=0.474\end{array}$ & $\begin{array}{l}1.097[0.539,2.230] \\
z=0.25 ; p=0.799\end{array}$ & - & $\begin{array}{l}1.871[0.486,7.205] \\
I 2=95.9 \% ; z=0.91 ; \\
p=0.362\end{array}$ & $\begin{array}{l}0.961[0.544,1.699] \\
I 2=0.0 \% ; z=0.14 ; \\
p=0.891\end{array}$ \\
\hline Ki-67: high vs. low & $\begin{array}{l}6.378[3.674,11.073 \\
] ; \mathrm{I} 2=30.1 \% \\
z=6.58 ; p<0.001\end{array}$ & - & - & - & - & - \\
\hline $\begin{array}{l}\text { premenopausal vs. } \\
\text { postmenopausal }\end{array}$ & $\begin{array}{l}0.963[0.716,1.296] \\
I 2=0.0 \% ; z=0.25 ; \\
p=0.804\end{array}$ & - & $\begin{array}{l}1.036[0.629,1.708] \\
\mathrm{I} 2=29.3 \% ; z=0.14 ; \\
\mathrm{p}=0.888\end{array}$ & $\begin{array}{l}0.874[0.571,1.339] \\
z=0.62 ; p=0.537\end{array}$ & - & - \\
\hline $\begin{array}{l}\text { TNM stage: III, IV } \\
\text { vs. I, II }\end{array}$ & $\begin{array}{l}0.825[0.220,3.095] \\
\mathrm{I} 2=81.4 \% ; z=0.29 \\
\mathrm{p}=0.775\end{array}$ & $\begin{array}{l}0.431[0.211,0.881] \\
\mathrm{I} 2=0.0 \% ; z=2.31 ; \\
\mathrm{p}=0.021\end{array}$ & $\begin{array}{l}1.268[0.684,4.050] \\
\mathrm{I} 2=0.0 \% ; \mathrm{z}=1.12 ; \\
\mathrm{p}=0.261\end{array}$ & - & - & - \\
\hline
\end{tabular}

\section{Figures}


617 Studies retrieved from PubMed, Embase, EBSCO, ScienceDirect, Cochrane

Database and the Web of Science

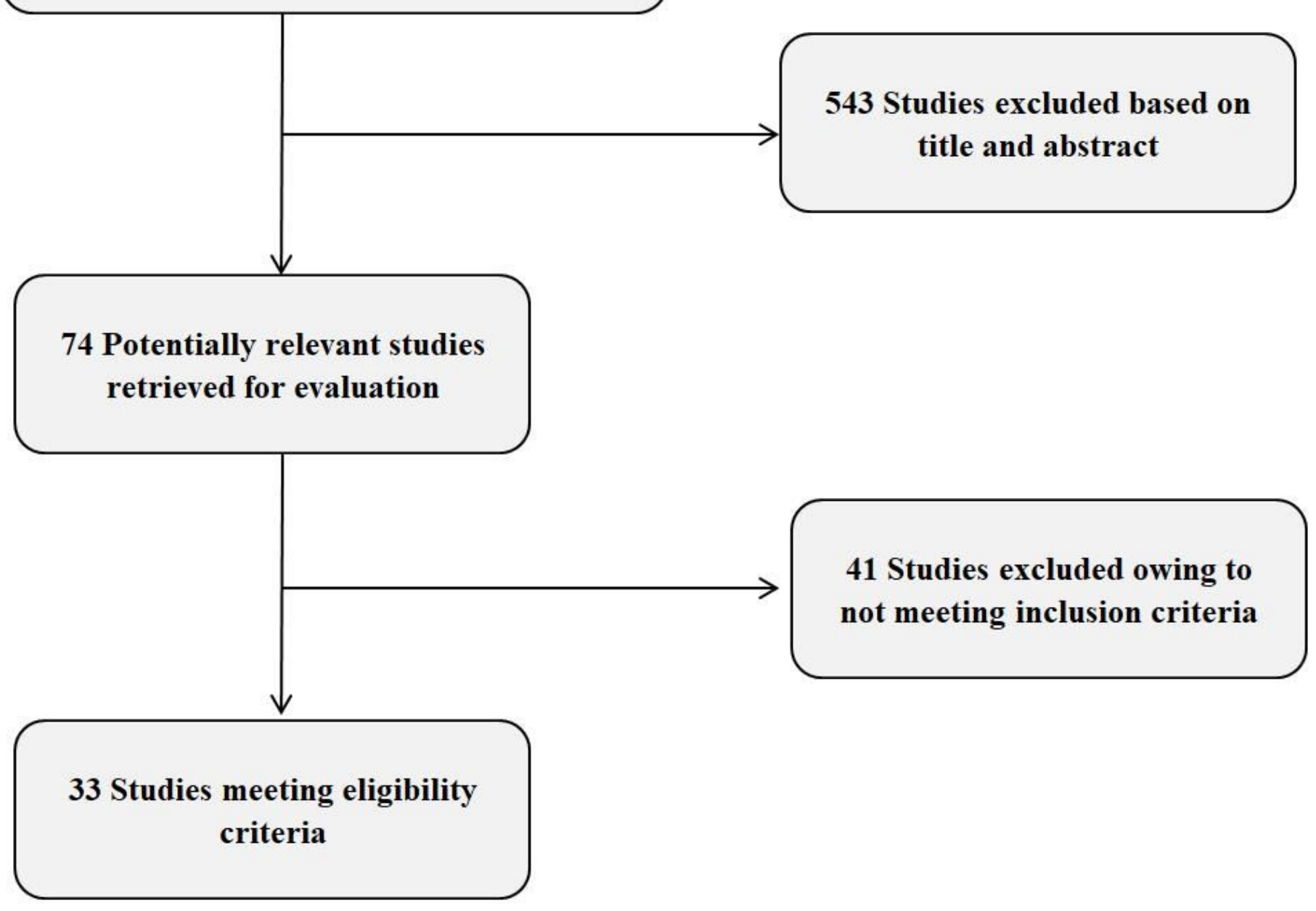

Figure 1

Selection process of included studies. 
Study

$\%$

ID

or $(95 \% \mathrm{Cl})$

Weight

$(\mathrm{D}+\mathrm{L})$

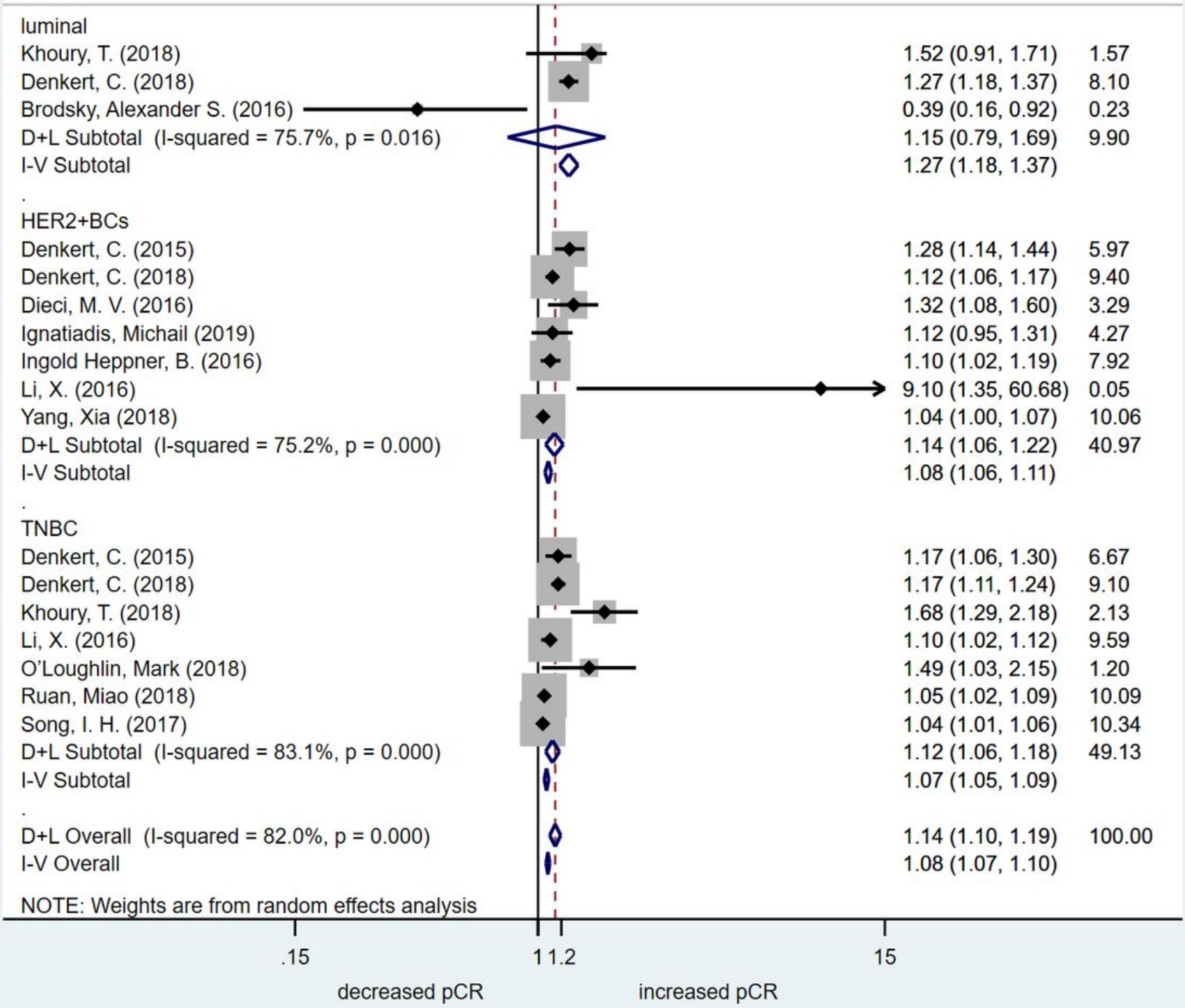

Figure 2

Forest plot of OR for pCR. Pooled assessing OR for pCR. 
ID

$\mathrm{hr}(95 \% \mathrm{Cl})$

Weight

$(\mathrm{D}+\mathrm{L})$

\section{luminal}

Hamy, A. S. (2019)

Fujimoto, Yukie (2019)

Loi, S. (2013)

Denkert, C. (2018)

$D+L$ Subtotal (I-squared $=0.0 \%, p=0.709$ )

I-V Subtotal

HER2+BCs

Denkert, C. (2018)

Yang, Xia (2018)

Ignatiadis, Michail (2019)

Salgado, Roberto (2015)

$D+L$ Subtotal $(I-$ squared $=63.6 \%, p=0.041)$

I-V Subtotal

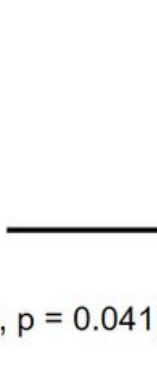

TNBC

Denkert, C. (2018)

Pruneri, G. (2016)

Song, I. H. (2017)

Adams, S. (2014)

Luen, S. J. (2019)

Leon-Ferre, Roberto A. (2018)

$D+L$ Subtotal $(I-$ squared $=78.0 \%, p=0.000)$

I-V Subtotal

D+L Overall (I-squared $=72.6 \%, p=0.000)$

I-V Overall

NOTE: Weights are from random effects analysis

1

.5

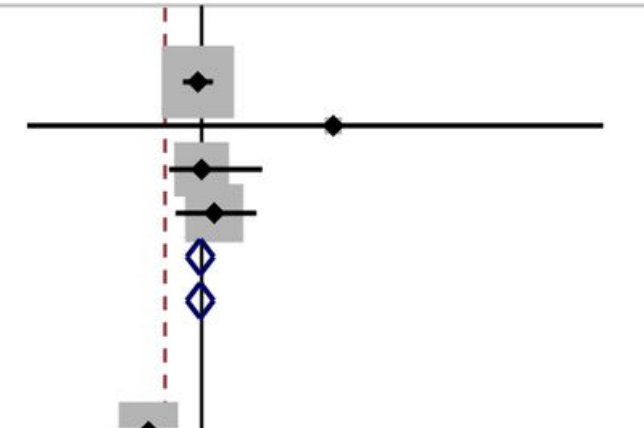

$0.99(0.97,1.02) 12.06$

$1.23(0.76,1.88) 0.31$

$1.00(0.95,1.10) 6.38$

$1.02(0.96,1.09) 7.34$

$1.00(0.98,1.02) 26.09$

$1.00(0.98,1.02)$

$0.92(0.86,0.97) 7.70$

$0.93(0.90,0.97) 10.43$

$0.75(0.56,1.00) 0.73$

$0.97(0.95,0.99) 12.36$

$0.94(0.90,0.98) 31.22$

$0.96(0.94,0.97)$

$0.91(0.85,0.97) 7.08$

$0.90(0.82,0.97) 5.48$

$0.98(0.95,1.00) 12.22$

$0.84(0.74,0.95) 3.19$

$0.86(0.78,0.93) 5.18$

$0.90(0.86,0.94) 9.55$

$0.91(0.86,0.95) 42.70$

$0.95(0.93,0.96)$

$0.94(0.92,0.97) 100.00$

$0.96(0.95,0.97)$

\section{Figure 3}

Forest plot of HR for DFS. Pooled assessing HR for DFS. 


\section{luminal}

Dieci, M. V. (2015)

Loi, S. (2013)

Loi, S. (2014)

Denkert, C. (2018)

$\mathrm{D}+\mathrm{L}$ Subtotal (I-squared $=0.0 \%, p=0.645$ )

I-V Subtotal

HER2+BCs

Denkert, C. (2018)

Dieci, M. V. (2015)

Yang, Xia (2018)

$D+L$ Subtotal $(I-$ squared $=0.0 \%, p=0.428$ )

I-V Subtotal

TNBC

Denkert, C. (2018)

Dieci, M. V. (2014)

Dieci, M. V. (2015)

Leon-Ferre, Roberto A. (2018)

Loi, S. (2014)

Luen, S. J. (2019)

Pruneri, G. (2016)

Adams, S. (2014)

$D+L$ Subtotal (I-squared $=0.0 \%, p=0.717$ )

I-V Subtotal

$D+L$ Overall (I-squared $=68.4 \%, p=0.000)$

I-V Overall

NOTE: Weights are from random effects analysis

.6
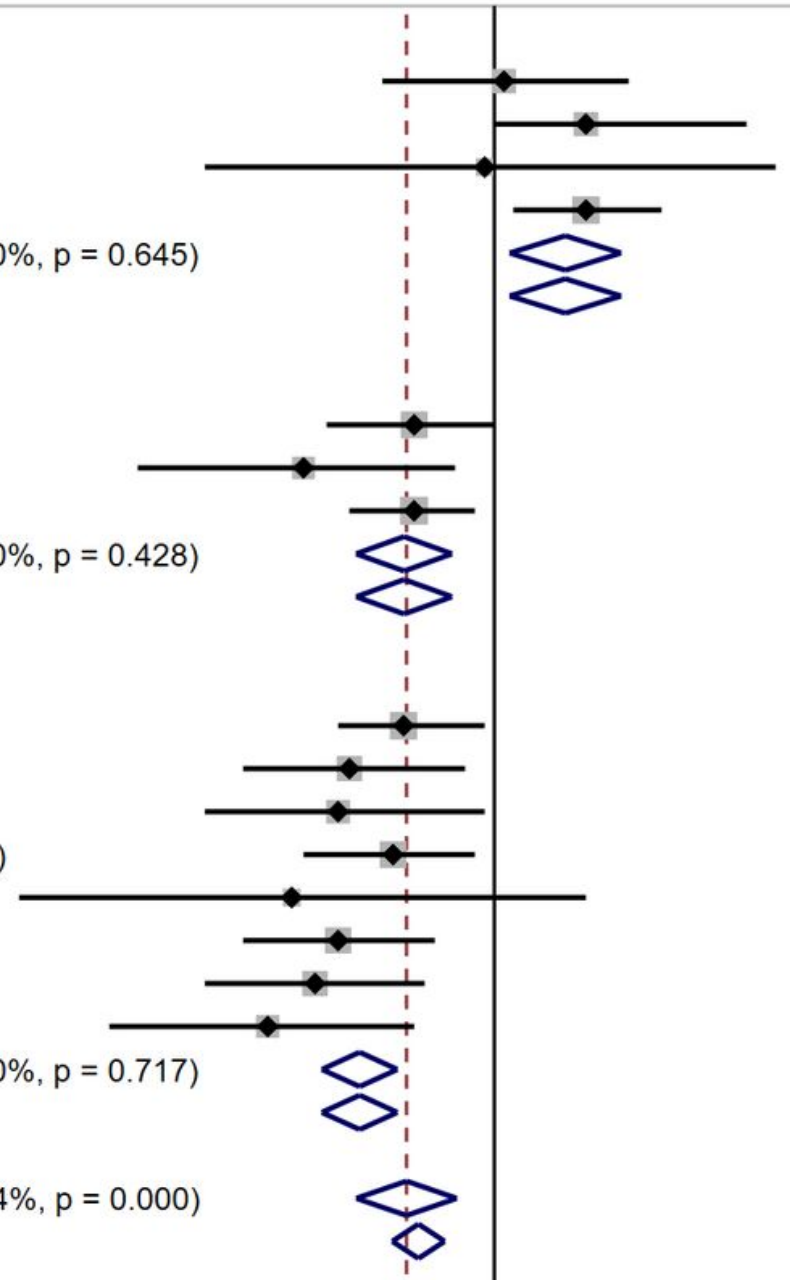

91

prolonged OS
$1.01(0.89,1.15) \quad 6.57$

$1.10(1.00,1.30) \quad 6.45$

$0.99(0.74,1.34) \quad 2.40$

$1.10(1.02,1.19) 8.80$

$1.08(1.02,1.14) \quad 24.23$

$1.08(1.02,1.14)$

$0.92(0.84,1.00) \quad 8.35$

$0.82(0.69,0.96) 5.21$

$0.92(0.86,0.98) \quad 9.31$

$0.91(0.87,0.96) \quad 22.87$

$0.91(0.87,0.96)$

$0.91(0.85,0.99) \quad 8.84$

$0.86(0.77,0.97) \quad 7.10$

$0.85(0.74,0.99) \quad 5.89$

$0.90(0.82,0.98) \quad 8.27$

$0.81(0.61,1.10) \quad 2.43$

$0.85(0.77,0.94) \quad 7.79$

$0.83(0.74,0.93) \quad 7.15$

$0.79(0.67,0.92) \quad 5.43$

$0.87(0.84,0.90) \quad 52.91$

$0.87(0.84,0.90)$

$0.91(0.87,0.96) \quad 100.00$

$0.92(0.90,0.95)$

\section{Figure 4}

Forest plot of HR for OS. Pooled assessing HR for OS. 

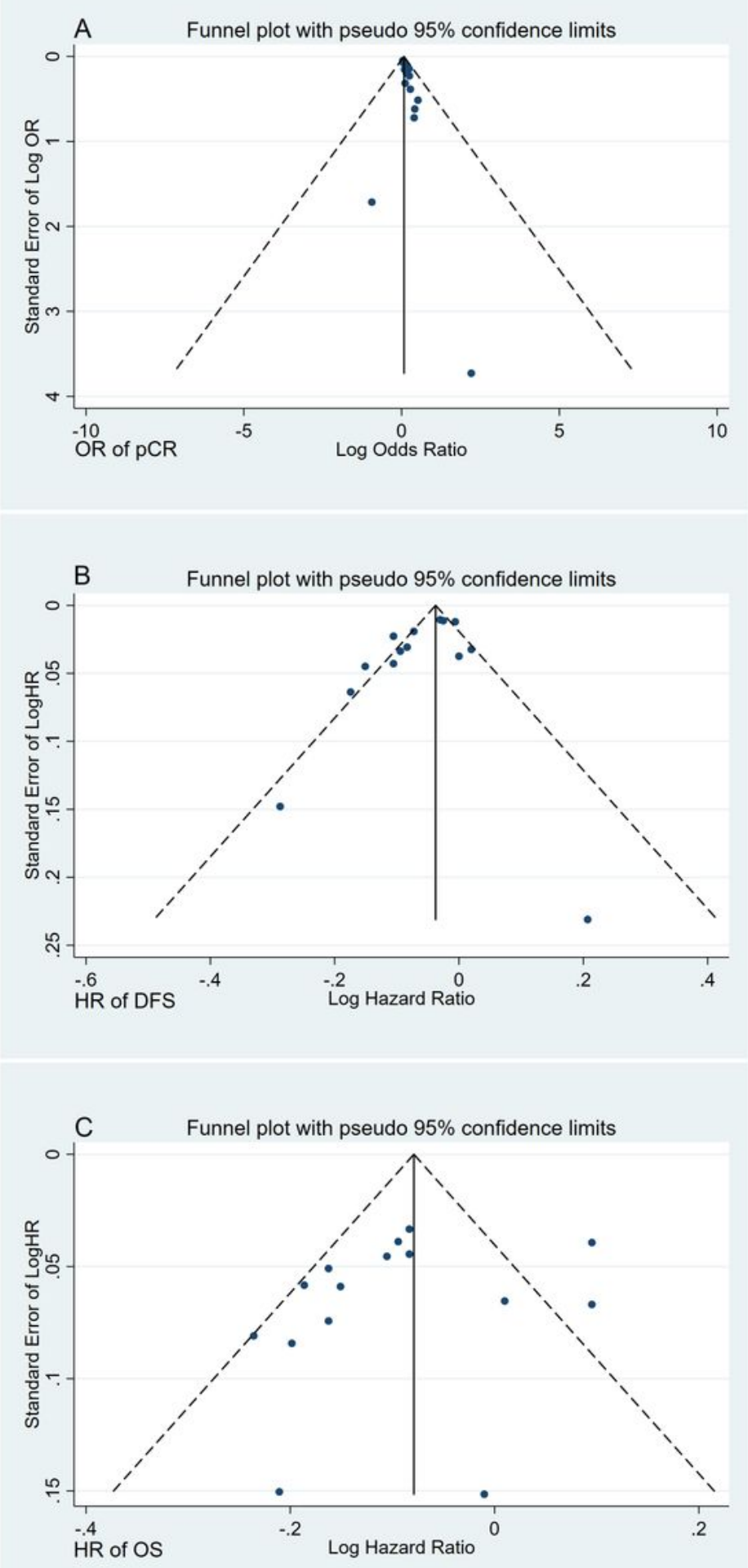

\section{Figure 5}

Funnel plot for potential publication bias. A: Funnel plot analysis of studies on pCR. B: Funnel plot analysis of studies on DFS. C: Funnel plot analysis of studies on OS. The funnel plot indicates that there was no significant publication bias. 